\title{
College Stress Survival Guide
}

\section{The Stressed Years of Their Lives. Helping Your Kid Survive and Thrive During Their College Years. By B. Janet Hibbs and Anthony Rostain; St. Martin's Press; New York, New York; 2019; ISBN 9781250113139; pp. 322; \$ 28.99 (hardcover)}

\author{
Richard Balon ${ }^{1}$ (D) \\ Received: 30 September 2020 / Accepted: 15 October 2020 / Published online: 22 October 2020 \\ (C) Academic Psychiatry 2020
}

College education is a very stressful affair for young adults and their parents, starting with the selection of a specific college and the focus of education, and continuing with management of financing, followed by the child' departure, that is, the child's physical and psychological separation from the family. Yet, these stressors are just the beginning for some students and families, as not all students are well prepared to leave home. Some of them are not emotionally resilient and cannot easily cope with suddenly failing a class, not being at the top of their class, or having to organize their studies on their own. Adding to this mix is the fact that these events all happen during late adolescence, euphemistically called early adulthood (or emerging adulthood as mentioned in this book), with all its emotional turmoil and during the time when many mental disorders start. No wonder that, as the authors of The Stressed Years of Their Lives, Janet Hibbs and Anthony Rostain, note, many students are caught in "the epidemic of college age mental health problems" (p. 4). They are not prepared for the roller coaster of college life and "for the removal of home's invisibly embedded emotional and cognitive scaffolding" (p. 5). Their parents are not prepared for their children's experience as well. Parents hope for college to be their children's best years of their life, yet they start to see "poor coping, anxiety, depression or emotional upheaval" (p. 4).

Seeing the dramatic rise in mental illness and other problems in college-aged students, Drs. Hibbs and Rostain, experts on late adolescent psychiatry and family psychiatry, wrote a guide on how to cope with the stress of the college years. Their writings, as they mention, are drawn on three wells of knowledge: scientific literature; interviews with students, parents,

Richard Balon

rbalon@wayne.edu

1 Wayne State University, Detroit, MI, USA high school principals, and college mental health personnel; and their decades of clinical experience helping young people. Their book is intended mostly for parents, but it can be of use to the entire family and others. It is composed of two parts: Part One, "Of Stress and Resilience," focusing on readiness and early identification of barriers to success, and Part Two, "Of Crisis and Recovery," discussing the lives of students and parents as they face both normative development and mental health concerns.

The first chapter, "On Fault Lines in the World of Today's Youth," outlines the issues faced by students and their parents, including the "gloomy forecast of increased competition and narrowing possibilities ("The college degree is becoming the new high school diploma" [p. 6]), economic uncertainty, the swiftly changing political landscape, 24/7 availability of the Internet, social media pressures, constant social and academic comparisons, competition with many, including their friends, and emerging mental health problems. Parents are stressed, too, and at times react with over-parenting, "which paradoxically hinders the emotional skills needed for a successful launch" (p. 7).

College mental health issues summarized in this chapter are frankly disquieting. Anxiety is the most common problem, with 1 in 4 college students either diagnosed or treated for anxiety in the prior year. Almost one-third of college students had trouble functioning due to depression. Depression, anxiety, and eating disorders are associated with a lower grade point average (GPA). More than $80 \%$ of college students feel overwhelmed, with $45 \%$ believing that things are hopeless. Minority students are less likely to seek help. "Suicide is the second leading cause of death among college students, claiming lives of 1,100 students each year" (p. 8). As mental health problems started to rise suddenly in the 1990s, colleges started to respond, investing more in mental health, especially in view of the prediction that approximately half of current students will seek mental health services at least once during 
their college years (p. 10). Yet many colleges and their health services were not prepared for this surge.

Some of the stress is not new, as Hibbs and Rostain write, as "the wreck of American childhood" is "habitual to periods of economic stress and rapid social change" (p. 13). However, they add that some of it is unprecedented, as automatization and globalization spur the decline of well-paid but low-skill jobs (p. 15) and parents feel that their children face "only three choices: college, the military, or a minimum wage job (i.e., failure)" (p. 14). The list of stresses goes on - growing independence vs. delayed arrival of fully adult roles; increased time in college (6 is the new 4), parents juggling too many demands, the world becoming more competitive and less forgiving, and helicopter parenting with over-preparation, overparenting, and over-investment. All that can also contribute to erosion of "traditional parenting authority, making it harder for parents to set limits and enforce demands" (p. 21). Hibbs and Rostain note that due to the enormous pressure to "enrich" the student's résumé, parents "forget that chores are good for kids and so are interests that aren't geared to the brag sheet" (p. 21).

The following chapter discusses social-emotional readiness and preparation for college. It reviews eight key components of social-emotional maturity that parents should explore and discuss with their children: conscientiousness, self-management, interpersonal skills, self-control, grit (i.e., readiness to cope with frustration, failure), risk management, self-acceptance, and an open mindset/help-seeking. The authors feel that "the real test of college readiness is whether a student can rise to the challenge of managing life on their own" (p. 35). The text includes a nice table on ways to overhaul one's smartphone use and reflective points for evaluation of one's interpersonal skills. The next chapter focuses on overcoming mindset barriers to success, namely, belonging (one has to have friends), the fear of not "making it," and emotional problems. Useful tables are included, such as one with tips for transfer students to smooth their transition. The discussion of emotional problems emphasizes that social stigma and selfstigma can discourage students from seeking help. The last two chapters of Part One deal with what parents should expect and do when their child has problems (e.g., what to ask, doctor shopping, questions to ask a therapist, early warning signs of mental health problems, and whether children should be forced to go to college or not) and how to plan and get through, especially with students who have compromised executive functioning (e.g., ask for instructional adjustment, optimize living arrangements, coaching, executive functioningoriented cognitive behavioral therapy).

The second part starts with a solid chapter on the adolescent brain in context of substance abuse, examining "the hazards, as well as the contexts, fueling the risk-taking behavior of college students" (p. 121). It addresses substance use and abuse (mentioning that marijuana may have negative effects on intelligence, cognitive functioning, executive functioning, and motivation) and misuse of stimulants. This chapter includes good tables on warning signs of emerging substance use disorder and of conversation tips for talking about substance abuse with young people. It concludes with a good list of resources. The following chapter focuses on anxiety and depression. The authors note, "Compared with their parents, the college students of today are 50 percent more likely to say they feel overwhelmed" (p. 149), facing multiple stressors as mentioned earlier. Quite useful are discussions on whether it is normal worry or anxiety disorder and whether it is sadness or depression. The text includes tables on how parents can help students and students can help themselves. Finally, this chapter includes excellent clinical vignettes (these true-to-life vignettes are mostly composites with changed names, except for one important case discussed through several chapters, which is that of Dr. Hibbs' son). This chapter is followed by a chapter on crisis care, focusing mostly on suicide.

A very interesting chapter on the "boomerang kid" and how to adjust to this type of child is revealing. The text informs us that "more people ages 18 to 32 now live with their parents than in any other arrangement - the first time this has happened in 130 years" (p. 208). Young people may return home during college (e.g., mental health issues, failure) or after graduation. The chapter discusses how parents can help the young adult's recovery through the expression of positive emotions (e.g., warmth, positive remarks, and regards) and avoiding harmful emotional expressions (e.g., hostility, emotional overinvolvement, critical comments). Useful is the advice on parental mental health and the stress of coping with the boomerang child, as well as tips for self-care. A related chapter on progressing from boomerang child recovery to relaunch notes that "boomerang suggests a temporary state, while FTL [=failure to launch] portends the young adult who never develops the skills that are vital for success in relaunch and life" (p. 233). The FTL phenomenon seems to be spreading through the developed countries. The authors warn of the trap of protection of these young adults and of the trap of accommodations, with classic signs of "a mutually reinforcing style that entraps parents and faltering young adults in a tangled web of diminished expectations" (p. 236). The chapter includes advice on how to deal with these young adults, with strategies for better mental health, including behavioral activation, and a number of lessons (e.g., do not lose hope, blend empathy with structure, better coping, better living with chemistry [= medications], eliminating bad habits, not being afraid to hold one's child accountable). The last chapter discusses recasting safety nets for all and provides more information on college mental health services. The book also includes an appendix with resources, including the authors' website.

This volume is very useful not just for parents of college students and their children but I believe that it would be useful educational reading for psychiatrists as well, particularly those 
involved in taking care of college students or "launching" their own children. It is thoughtful, full of interesting information, based on a wealth of experience, and easy to read. The authors provide us with much insight to the life and problems of college students and advice on how to improve their wellbeing. Educators among us may use some of the presented wisdom to deal with resident problems (as I used to tell our residents, residency training seems to be like a "second adolescence" at times). For me, the book also raises a more philosophical question: Does everyone need college education if it is so stressful? And is college education fulfilling its role if other countries get by without it? But those are questions for another book.

\section{Compliance with Ethical Standards}

Conflict of Interest The author states that there is no conflict of interest.

Publisher's Note Springer Nature remains neutral with regard to jurisdictional claims in published maps and institutional affiliations. 